\title{
MUSEUMS AT THE CROSSROADS: BETWEEN DIGITALITY, REALITY, AND COVID-19
}

\author{
Tula Giannini \\ School of Information \\ Pratt Institute \\ New York, USA \\ giannini@pratt.edu
}

\author{
Jonathan P. Bowen \\ School of Engineering \\ London South Bank University \\ London, UK \\ jonathan.bowen@1sbu.ac.uk
}

\begin{abstract}
When Covid-19 rushed into our lives, it sent shockwaves across the globe - suddenly we faced "lockdown" - we said goodbye to the way it was but did not understand what this brave new world of isolation and separation would mean and how it would the impact life as we knew it- our identity, relationships and freedoms we enjoyed, and wondered what daily routine postCovid-19 would look like, while the experiences defining life itself were up for grabs. With social distancing, masks and work from home mandates, the arts and performing arts from theatres, museums, galleries and the public square were shuttered - their very existence challenged and spiralling out of control as staff were laid-off, exhibitions cancelled while concurrently creating an urgency to go online to dwell in cyberspace, the new daily destination.
\end{abstract}

\section{INTRODUCTION}

The crisis of the pandemic, now converged with critical sociocultural movements and technological advances in AI, robotics and computing in ways that question human identity and purpose, are trends that had already intensified by summer 2019. As the world sought to navigate through this unprecedented and life changing disruption, the rising digitality of our states of being pushed us evermore toward virtual life. With remote work, we witnessed the emptying out of the public square leaving a lacuna of human activity and social interaction. The social forces already at play of diversity, equity, and inclusion, burst into this deserted space and filled it with protest fuelled by social movements most prominently, Black Lives Matter. This paper explores these issues through the lens of museums and cultural life, where art pervades the fabric of life, and is heard and seen on city streets, in galleries and museums. We look at how arts and cultural life have evolved from 2019 to 2021 and how museums might survive during this time of dramatic change and uncertainty, accelerated by the social forces influencing human identity and relationships.

$\begin{aligned} & \text { Covid Commons } \\ & \text { by T. Giannini }\end{aligned}$
Alone
At home
Just my smartphone
What are my choices
TV voices
Fake news
That's your muse
Netflix
Take your picks

\author{
Don't tweet \\ or take the heat \\ You're in retreat \\ Escape from Amazon \\ End the marathon \\ Ask Google \\ Where's life gone \\ Mickie and Minnie \\ could be Winnie \\ a dream sequence - \\ with no evidence
}

\author{
Can't get back \\ to reality \\ Stuck in virtuality \\ Main menu \\ No venue \\ for physical experience \\ The materiality \\ of holding hands \\ Kissing \\ Missing \\ you
}




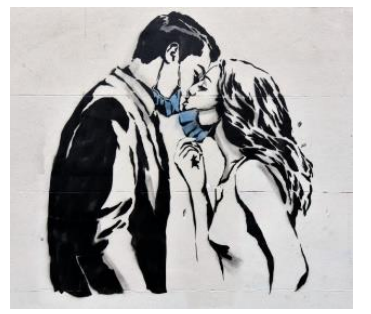

Fig. 1. Illegal graffiti in Glasgow, by Daniel Naczk, 9 April 2020.

This Covid graffiti symbolises emotions behind the mask - the illicit and the illegal. That which is natural becomes taboo.

https://commons.wikimedia.org/wiki/File:Glasgow. Bank Street. Graffiti._jpg.jpg

Well before the pandemic, museums had already made a paradigm shift from being collection-centric to user centric in the context of human participation and interaction. When Covid-19 struck, museums had no choice but to turn to digital transformation, although there was little digital to be seen onsite - even digital art was mostly excluded. Suddenly, museums faced with the Corona virus crisis, saw their doors shuttered, the visitors gone - and so was their main revenue and income. Libraries also closed but the stakes were not the same as their main menu, the book, is served well by the digital book, a great surrogate of growing popularity, surpassing the physical book in many ways. Whereas the physical collections of museums, their main menu, is defined by their physicality, their size, shape, colour, texture, materials and the spaces they occupy in galleries, all of which are central to how we experience a work. As the tension between physicality and digitality grows the longer Covid-19 continues, the more human behaviour adopts to altered states of being digital while the public square, the place where people gather and socialise, shrinks, we find ourselves in retreat from the life we knew as big tech and big government occupy the void. When the pandemic ends, that life that once was, will end too, invoking somewhat of a Rip Van Winkle effect.

What will happen to the public places we abandoned during Covid-19, and what will motivate people to come back, and will museums be able to attract new audiences. Enter digital artists, designers, and museum curators - those who know how to use digital to make art and engage audiences, to tell stories and be contemporary and relevant. Digital artists, whose presence in museums seems sorely lacking must now assume a more central role in digital integration and visualisation of human digitality and identity. While information and technology services can be outsourced or remote, curators remain at the heart of defining collection content and context and more than ever, recognise the need to collaborate with artists on new narratives, which in turn opens up museums to reimagine collections in ways that encourage them to engage with more diverse communities, artists and audiences.

\section{COVID-19 AND DIGITAL LIFE}

Remote work and online education confines people to their homes. People retreat as cities seem lifeless and begin to die and have themselves become diseased. People begin to leave city centres to seek their own space saying goodbye to those tall buildings with hundreds of apartments and offices that begin to look more like prisons. Cars, like private spaces on wheels, are the refuge between here and there as we avoid public space at all costs while public transportation seems deserted. Being locked-down in our homes and locked-out of real-life causes feelings of disorientation, displacement, and dissolution of life as we knew it. Seeing art, seeing life and human interaction moves to digital screens, as our sense of physicality fades, replaced by virtual experience, as when the size of an artwork becomes the size of the screen - digital simulation of physical attributes replace the real and are lost to digitality. 


\section{Seeing Digital in Art Museums - Immersive Reality and Virtuality}

As we progress through the 2021 pandemic, seeing digital in art museums and in exhibitions still has not been broadly conceptualized and accepted, lacking regular space, place and purpose as digital mainly serves museums' online presence, and seemingly disappears entering the physical museum where digital is generally represented by visitors' smartphones or iPads. Extending physical reality in museums using VR, AR, MR, and 3D awaits broader use and regularization. Where VR has been cultivated to a high degree to enhance visitor experience, for example the 2018 Modigliani Exhibition at the Tate Modern, the Louvre's Mona Lisa Exhibition as part of the 2019 da Vinci Exhibition celebrating 500 years since his death [4], it has received wonderful results and wide acclaim. For both of these exhibitions, the museums partnered with VIVE Arts. Now in 2021, a new foray into VR and integrated digital, arrives with the V\&A (Victoria and Albert) Museum's exhibition, Alice: Curiouser and Curiouser, planned to be on view from 27 March 2021, features a VR experience created by VIVE Arts that can also be viewed in an online version [5].

At the heart of the V\&A's exhibition's Conjuring of Alice, are curators, digital artists, and designers of the creative industries working collaboratively. The overwhelming critical success and broad public enthusiasm for the VR components of these exhibitions as well as other digital enhancements, points to the need for museums to cultivate inhouse digital artists/curators to be part of their team for exhibitions, working onsite and online in ways that heighten visitor experience while also accounting for their digital behaviour.

Post-Covid, the playing field of exhibitions and visitor experience will have forever broadened its scope to include an ever-expanding range of virtual technologies that in the first instance expand the artistic palette for creating exhibitions and other visitor experiences serving to inspire public learning and emotional engagement, as museums tell new stories in relevant ways. The Alice exhibition does just that, while bringing new and thought-provoking interpretations, it takes the visitor on a journey spanning 156 years, beginning in 1865, the year Alice was first published, arriving at 2021, a moment of global pandemic, when we all, to some extent, have fallen down the rabbit hole of virtuality.

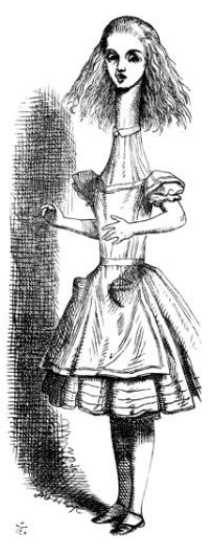

$\begin{array}{ll}\text { The Digital Abyss } & \text { Can't recognize where I am } \\ \text { by T. Giannini } & \text { Virtual life seems out of hand } \\ \text { The past fades } & \text { Exhibitions and legacy systems } \\ \text { As we wade } & \text { Old traditions } \\ \text { deep into a rabbit hole } & \text { Falling apart } \\ \text { down under the grassy knoll } & \text { Cancelled ambitions } \\ \text { of the digital abyss } & \text { New renditions } \\ \text { Following Alice into Wonderland } & \text { disappearing the past } \\ \text { take my hand } & \text { The die is cast } \\ \text { entering remote identity } & \text { Can't hear your voice } \\ \text { in virtual reality } & \text { No choice } \\ \text { It's all a sham } & \text { Time's run out }\end{array}$

Fig. 2. Left: 1865 illustration by John Tenniel for Alice in Wonderland, $1^{\text {st }}$ ed., Morphing identity.

The topsy-turvy world of Alice finds deep concordances with life in the virtual world. Alice leaves her real world and enters a simulated virtual world of "wonderland," as contemporary life has fallen down the "rabbit hole" of Covid-19. 


\section{Museums - Integrating Real and Virtual}

When we re-emerge from the void of Covid life, how will we put reality back together? The lacuna in the public square left by Covid has veered from occupied to empty, stranded between lockdowns and protests. Filling that void in a physical sense, and in our hearts and minds presents an existential challenge to human existence - life as we knew it and what it might become. Museums are now asking, what will be a sustainable model of the future under the impact of the emerging principles of digitality. The book Museums and Digital Culture [3] takes up the notion of the museum beyond its walls, bridging to community, local and global, and merging the museum's online identity with that of the physical museum, and re-thinking how museums can generate income, and what might be the new partnerships, new roles for government and philanthropy. Some initial considerations might be found in those that build on existing resources and strengths. The book devotes a chapter to museum education through the lens of the Master's in Museums and Digital Culture, introduced by Giannini at Pratt Institute, which in many ways explains and looks beyond 2021.

As AI and machine learning prevail in this moment of crisis, for the first time in human history artificial intelligence challenges human intelligence as humans bow to the machine power of the fourth industrial age. Humans and machines working together are engaging millions if not billions of people - but as AI invades more of the things of the mind, human thinking, imagination, and creativity, - what will be left to humans - will we need to be more than human? The first to go is repetitive, make-a-day work, which is broadly embedded in our institutional legacy systems including those for archives and libraries. At the very moment university students turn to technology as the answer to "getting a job", will some of those jobs go to AI and human personification - robots. Learning to write and operate programs, soon will be dominated by big tech and communication corporations, most humans will simply follow program instructions, buy the product, play the games, and watch the shows.

Art and artists are the future in a future where creativity, critical thinking and free expression can exist. Digital art now moves to centre stage - using digital tools to expand our mind and vision and interpreting through computational culture, we seek a new sense of aesthetics that speaks to all cultures as cultures worldwide see themselves and others through a digital lens. How much will humans morph to live side by side with robots and see the world through screens.

\section{COVID CONFLICTS AND IDENTITY}

Information and communication corporations are becoming larger, offering each person their place in the digital ecosystem. Governments are being cowed by giant-technology companies (Google, Facebook, Twitter, etc.), social order is disintegrating, and the large news media corporations represent the reality of social and cultural revolution through a digital lens - we were not prepared. During Covid, some cities have become centres of protest witnessing a new movement of migration from large cities and life at the precipice of a radical shift where each human is at the centre of creating their identity - choose your gender, choose your religion, choose your age - but you can't choose to live outside of the digital ecosystem - where there's still lots of room at very little cost - life in the cloud, on a platform - where being unplugged means death - who are you anyway - a place where big tech corporations are all about serving individual customers and consumers. What are they serving - information - products - 
experiences - entertainment - services - customization. But we wonder, are humans the customer or the product?

\section{The End of Reality - Simulating Life, Art, and Identity}

Like many other periods of transformation, revolution and re-invention, in the early stages are attempts at simulation of what was and then using a new media - for example, in 1968, Harriet Avram changed library catalogue cards to machine readable cards - and the MARC record is still be used! In our computational culture, we are trying to simulate the real experience of education on location at a school to online as a sort of virtual classroom, but we increasingly see that online courses have little in common with the totality of real experience, one that is highly complex existing in time and space between where physical and digital converge, and where the digital is used to heighten the human experience in the physical world. Now, during Covid, the new goal is to create a digital simulation of what was reality and convince people that it can and will be an improvement. There is a sense that reality is a thing of the past and is "old school".

The key symbol of Covid, the mask covering the nose and mouth produces a sense of fear and isolation, and potential punishment for not following rules, like "go to your room" - do not come out until we tell you the coast is clear and it is safe to step out. In the past, we had "masked balls" but the mask did not cover the mouth. Instead, it concealed identity, while communicating intrigue and an invitation to become acquainted. Acquaintance has not been acquitted, but rather seems omitted from daily life reinforcing feelings of isolation. Museums depend on academe to prepare students for careers in museums at the heart of which is curatorship and cultural leadership. Looking back over centuries, we see that apprenticeship has yielded the most significant and tangible results. This long-established mode of learning has been significantly curtailed and will impact students' ability to understand the curatorial side of museum work.

\section{DIGITAL CAPTURE AND CURATION}

Digitization remains foundational for museums and the humanities generally. Recent advances in computing as computer recognition across media - image, text, sound, video, 3D, VR, AR, and MR, offers new opportunities for creative, innovative and integrated processes and applications on a large scale, moving from the legacy labour-intensive models and systems that take item by item approaches tied to human selection, tagging, cataloguing, organizing, etc., when there are digital tools using AI and machine learning that can automate these processes. Importantly, this would greatly increase capacity, access, and use. Museums, archives and libraries need to collaborate and share across institutions to find ways to automate their processes to be more plug and play. Given that digitization is a repetitive process, it lends itself to AI and machine learning that can accommodate the intelligent aspects normally assigned to human intelligence such as metadata schema and search.

Covid has raised the stakes on implementing and investing in new intelligent systems with the promise of reduced labour costs and increased productivity, while for archives it addresses hidden collections, broadens selection reducing prejudices inherent in individual selection and in authority knowledge systems. Soon, repetitive work will be superseded by automated systems, and this will be the case in the museum, archive and library world, freeing-up professional staff to focus on critical tasks requiring high-levels of human intelligence, 
creativity and abstract thinking as museums become more welcoming to digital innovation, fresh interpretations and socially relevant storytelling. With this approach, collections come alive and are open to discovery from the dual-perspectives of curators, visitor and users - so, a more inclusive democratized systems with sharing for cost-reduction of routine activities that are not main menu, while favouring more investment in artists, exhibitions, curatorial, creative computing and research.

\section{Between Two Worlds - Real and Virtual}

We have entered a new period of experimentation and research at the crossroads where before us, are an unprecedented number of choices all leading to degrees of transformation of our ways of being and knowing ourselves and the word. As we leap into the fourth industrial revolution of $\mathrm{AI}$ and machine learning under the forces of Covid, social and cultural revolution - it seems we have little choice but to accelerate change and dive into the future. However, lockdown has limited our choices as it imposes a more artificial and virtual life, dependent on new digital services from the realm of education to shopping, dining, entertainment, and in the first instance - communication. Some sectors of society are raking in more money than ever digital entertainment, communication and online commerce - while others, libraries, archives, museums and education are in search of a new order, which most likely appears to be a huge leap towards digital dominance, shifting to digital frameworks beyond information management systems - but rather extending to human behaviour and interaction systems - not big data per say, but increasing levels of digital embedded in day to day life - the "Internet of Behaviour" that guides, monitors and controls human behaviour. For example, emerging from the Covid crisis, systems have developed for "contact tracing" a huge experiment in imposing specific behaviours on the global population that seem unprecedented.

Museums are being lured by the big corporations such as Disney, Netflix, and Amazon not just for sponsorship but rather collaboration. Social justice movements receive top billing in art and education. Digital globalism fuelled by the Internet's digital ecosystem over platforms and networks and created by the new phenomena of digitality dominating human behaviour and interaction, wildly increased by Covid, so that we are propelled into unknown territory challenging human identity. The so-called fourth industrial revolution challenges traditional notions of living, communication and interacting in the world as AI and ML become embedded systems for day-to-day human functioning simulating, reinventing and assuming roles once reserved for humans. This emerging collaboration between humans and computing machines using AI and robotics - means that human abilities for creativity, innovation and critical thinking take on new importance as does human judgement, values and ethics. Rapidly increasing levels of digitality in day-to-day life, almost imperceptibly are transforming the nature of human experience and what it means to be human. Between elation and fear, digital engagement and isolation, the old and new order, the unstoppable force of the digital revolution is mirrored by a new social revolution of human identity and equality driving social unrest.

\section{Museums - A Prelude to Covid-19}

In the current crisis-leaden environment, the old road is rapidly aging and being replaced by a new Internet highway constructed around AI and neural networks for virtual life in cyberspace and physical place as we reach out through Zoom in a world where legacy systems 
are disappearing and being replaced by digital infrastructures simulating human experience and senses from the IoT to the IoB (Internet of Behaviour).

Looking to the future from the vantage point of the present, a period of extreme change is before us, during which Internet communication, computing and AI are the key drivers of a new social order, as human behaviour and experience under the weight of Covid-19 is causing a surge of digitality in everyday life. For example, education moving en masse to online, shopping online reaching unprecedented levels of participation and e-books and other forms of digital information holding sway among users. During the same time, museums, libraries, and archives were forced to close and move online leaving behind their traditional modes of operating in the physical museum for a virtual presence on the Internet. Thus, these institutions, especially museums, are scrambling to find alternative paths to financial sustainability [6].

Although ultimately, the answer will be in an integrated model of onsite and online, during the next year or two. One approach might be partnerships with corporations such as Netflix and Disney as well as seeking commercial sponsors of exhibitions who might also contribute to the show itself. Museums might consider fee-based programmes by expanding their education programmes to include credit degrees such as a master in museums drawing on existing resources, collections and curators, and having deepened their online presence and connection to their audience, museums are becoming more adept at using 3D, AR, VR, MY, and AI. Over time, such degree programmes could become hybrid, adding focus to experiential learning onsite. Further, there is a need for museums programmes that prepare professionals to engage the social and curatorial challenges of the field as they strive to speak to a more diverse audience and can be especially effective in visual modes of communication, the modes du jour as the old text-dominated world fades.

Despite the advance of digitality being unstoppable, as noted in our articles on digitalism [1] and digitality [2], there are critical choices in how and where it is applied, why and for what purpose and outcomes, how it serves and enhances human experience, education and quality of life, and importantly, the roles and responsibilities reserved for human work and participation, that will more and more be a measure of human relationships with AI systems and robots.

McKenna [7] poses the question: "At a time when museums and art galleries have closed their doors to art lovers, has the time come for digital art? Art that has been digitized, but also Art that is born digitally, especially video art?" The Israeli start-up company, Niio, is developing a platform for digital art that draws on the Netflix and Spotify platform model to publish and view digital art that bonds artist and artifact using blockchain and AI. The founder and CEO of the company "believes Covid-19 has sped up the growth of digital art, and that technology holds the key to the future of the art sector."

\section{CONCLUSION}

What remains to be addressed were museums to embrace digital - what would that look like? At this critical juncture, what seems most needed are fresh insights for new conceptual models that bring creative ideas to identify structural change and a move away from old-school notions, legacy systems and identifying digital tasks that can be outsourced while others are redefined. Still the question remains, how will museums accommodate rapidly evolving human digital behaviour and expectations? What museum activities sit at the core of museum transformation. How will museums marshal their precious resources so that when post- 
pandemic visitors return - things will not look the same - but rather, more exciting, visually engaging in ways that integrate digital life and that define a spirit of creativity and innovation - so not dusty, not old, not unconnected to the current environment presenting fresh museum stories, narratives and relationships past to present, that show awareness of social issues of diversity, inclusion and equity.

Much emphasis has been afforded social media in particular Twitter and Instagram to understand museum audiences, yet social media sits in the realm of visitors, while social media analysis goes to Google - and mapping and searching collections, can go to Google and Microsoft. So, what can museums do that plays to their strengths and values. The answer is somewhat before us - look at what visitors see and experience and ask how museums can enhance and expand that visual and social experience.

The greatest challenges for museums will be finding new models for sustainability, able to respond to the complex challenges posed by the contemporary cultural landscape. Designing these models that encompass onsite and online, inside, and outside, and their integration while focusing on visitors and community relationships, understanding and inclusiveness. Museums need to play a greater role in education and consider its income possibilities, for example, offering master's degrees to prepare museum professionals to meet the critical challenges of digital and cultural transformation. While libraries and universities are hugely subsidized by public funding, museums have relied on financial models that seem more akin to amusement parks and entertainment. Museums need to realign their missions in ways that increase social engagement, teaching and learning, and reaching out to more diverse audiences, while not being so dependent on tourism, especially since Covid has greatly reduced travel.

Museums must now broaden their mission to include contemporary contexts of art, education, human identity, and life itself. By so doing, they move to being an essential part of the social fabric of urban life, to arrive at a general recognition that without museums, we are surely less human, less informed about our past and what our future might be. Yes, we are at the crossroads of an unprecedented digital and cultural transformation rapidly emerging from the Covid crisis, and we can see that museums are responding with a new sense of purpose and connection to diverse audiences and cultures. Buoyed by the diversity of the global digital ecosystem, museums are poised to embrace digital artists and digital culture as intrinsic to a new sense of identity and purpose - surely a museum renaissance is in the offing [4].

\section{References}

[1] J. P. Bowen and T. Giannini, "Digitalism: The New Realism?", in K. Ng et al., EVA London 2014: Electronic Visualisation and the Arts, BCS, eWiC, 2014. 10.14236/ewic/EVA2014.76

[2] J. P. Bowen and T. Giannini, "Digitality: A reality check", in J. Weinel et al., EVA London 2021: Electronic Visualisation and the Arts, BCS, eWiC, 2021. 10.14236/ewic/EVA2021.0

[3] T. Giannini and J. P. Bowen, Museums and Digital Culture: New Perspectives and Research, Springer, Series in Cultural Computing, 2019.

[4] T. Giannini and J. P. Bowen, "The Digital Renaissance from da Vinci to Turing", EVA 2020 Florence, SocArXiv, 2020. https://doi.org/10.31235/osf.io/h5fm4

[5] Preloaded, "Curious Alice”, V\&A \& VIVE Arts, 2021. https://preloaded.com/work/curious-alice/

[6] E. Kinsellam, “We'd Love to Work With Netflix Again': Cash-Strapped Museums Looking for New Audiences Are Increasingly Doing Exhibits-for-Hire”, Artnet News, 4 January 2021. https://news.artnet.com/art-world/its-a-deal-is-the-rise-in-museum-sponcon-linked-to-lockdown-1933514

[7] B. McKenna, "Is digital art coming of age under Covid?", Computer Weekly, 3 July 2020. https://www.computerweekly.com/news/252485614/Is-digital-art-coming-of-age-under-Covi 